\title{
LA REDUCCIÓN DE JORNADA COMO MEDIO PARA CONCILIAR LA VIDA FAMILIAR Y PERSONAL
}

\author{
LARA M. MuNÍN SÁNCHEZ \\ Juez sustituta \\ Doctora en Derecho (acreditada como PCD) \\ Profesora Asociada de la Facultad de Ciencias del Trabajo (UDC)
}

Fecha de recepción: 30.6.2016

Fecha de aceptación: 11.8.2016

\begin{abstract}
Resumen: La conciliación de la vida personal, familiar y profesional es una de las manifestaciones más importantes para lograr, entre otros objetivos, la igualdad efectiva de hombres y mujeres, esto es, la participación equilibrada entre mujeres y hombres en la vida familiar y en el mercado de trabajo, mediante la reestructuración y reorganización de los sistemas, laboral, educativo y de recursos sociales, con el fin de introducir la igualdad de oportunidades en el empleo, variar los roles y estereotipos tradicionales, y cubrir las necesidades de atención y cuidado a personas dependientes. Uno de los medios para conseguirlo -aparte de otros muchos- será la reducción de la jornada de trabajo, de tal forma que se pueda acortar el tiempo dedicado a la prestación de servicios, aunque suponga una reducción correlativa del salario. La cuestión es cómo se hace en caso de que existan discrepancias con el empresario y, sobre todo, en qué medida se diferencia jornada y turno, para el caso de que el sistema de trabajo implementado en la empleadora sea de esa naturaleza; y el presente artículo trata de responder al tema.
\end{abstract}

Palabras clave: jornada; conciliación de la vida personal, familiar y profesional; turno de trabajo; proceso laboral

Abstract: Reconciling personal, family and professional life is one of the most important appearance to involve, among other objectives, the effective equality among men and women, namely, balanced share among both of them in family life and in the labour market, by restructuring and reorganization the systems, labour, educational and social resources in order to introduce equal opportunities in employment, change 
traditional stereotypes and roles, and needs attention and care for dependants. One of the ways to achieve it - apart others - will be the reduction of the working time, so that you can shorten the time spent on the provision of services, although it involves a correlative wage's reduction. The question is how in the suppose that there are discrepancies with the employer and, above all, the differences between working time and shift work, if this is the implemented way of work at company; and this article tries to respond to this issue.

Keywords: Working time; Reconciling personal, family and professional life; Shift work; Labour process

SUMARIO: I. APROXIMACIÓN AL TEMA. II. EL TIEMPO DE TRABAJO. LA JORNADA. III. LA CONCILIACIÓN DE LA VIDA PERSONAL, FAMILIAR Y PROFESIONAL. 1. Formas de hacerlo efectivo. 2. Procedimiento para dirimir las discrepancias. IV. CONCLUSIONES.

\section{APROXIMACIÓN AL TEMA}

1. La conciliación de la vida personal, familiar y profesional es una de las manifestaciones más importantes para lograr, entre otros objetivos, la igualdad efectiva de hombres y mujeres, esto es, la participación equilibrada entre mujeres y hombres en la vida familiar y en el mercado de trabajo, mediante la reestructuración y reorganización de los sistemas, laboral, educativo y de recursos sociales, con el fin de introducir la igualdad de oportunidades en el empleo, variar los roles y estereotipos tradicionales, y cubrir las necesidades de atención y cuidado a personas dependientes. Se ha llegado a definir como «una estrategia que facilita la consecución de la igualdad efectiva de mujeres y hombres. Se dirige a conseguir una nueva organización de sistema social y económico, donde mujeres y hombres puedan hacer compatibles las diferentes facetas de su vida: el empleo, la familia, el ocio y el tiempo personal. Por tanto, la conciliación de la vida familiar, laboral y personal contribuye a crear una sociedad basada en la calidad de vida de las personas, primando las mismas oportunidades para las mujeres y los hombres con el fin de poder desarrollarse en todos los ámbitos vitales, progresar profesionalmente, atender las responsabilidades familiares y poder disfrutar de tiempo, tanto familiar como personal» ${ }^{1}$. La igualdad entre mujeres y hombres, que postula como fin y generalmente como medio la parificación, impone erradicar de nuestro ordenamiento normas o interpretaciones de las normas que puedan suponer la consolidación de una división sexista de papeles en las responsabilidades familiares ${ }^{2}$; y así lo ha entendido la Sentencia del Tribunal de Justicia de la Unión Europea de 30 de septiembre de 2010, asunto C-104/2009, conocida como Asunto Roca Álvarez. Porque no puede perderse de vista- «[d]urante muchos años se insistió exclusivamente en la

\footnotetext{
${ }^{1}$ Véase FUNDACIÓN MUJERES, Conciliación de la vida laboral, familiar y personal, Ministerio de Igualdad, Madrid, 2010, p. 5.

${ }^{2}$ Véase la Sentencia del Tribunal Constitucional núm. 26/2011, de 14 de marzo, Fundamento Jurídico núm. 5.
} 
necesidad de acabar con la discriminación por razón de sexo en el acceso y la continuidad en el empleo, de manera que la mayoría de las normas dictadas fueron encaminadas a conseguir la igualdad de oportunidades entre ambos sexos. En consecuencia, no se tuvo en cuenta que las diferencias por razón de sexo en el empleo son en realidad un reflejo del distinto papel que hombres y mujeres asumen en el seno de la familia. Así, es una realidad constatada que paralelamente a la incorporación de la mujer al mundo laboral se ha producido un aumento del número de mujeres que se dedican simultáneamente al trabajo dentro y fuera del hogar familiar, lo que da lugar a una "doble jornada de trabajo", como gráficamente se ha expresado»" ${ }^{3}$.

Existen múltiples medios para conseguirlo (entre ellas, medidas de que amplían y mejoran la normativa; las de flexibilidad en la distribución del tiempo de trabajo y en el espacio del trabajo; las que sirven para acercar los servicios para el cuidado de personas dependientes; las que configuran una cultura empresarial que valora el que su personal tenga articulada su vida laboral con la familiar y personal; y, finalmente, las medidas complementarias que facilitan mejorar la calidad de vida de las personas trabajadoras) y con muy distintos resultados $-\mathrm{y}$ vías $-{ }^{4}$, pero la que interesa a los fines de este artículo científico es la reducción de la jornada de trabajo, de tal manera que se reduzca el número de horas en las que el trabajador o, casi exclusivamente, la trabajadora ${ }^{5}$ presta servicios para su empresa para poder dedicarlas a su vida personal o familiar, lo que ocurre es que esa reducción supone otra correlativa del salario del empleado, por lo que su opción es muy onerosa para la persona trabajadora, pero que hubiese sido mucho más efectiva si se hubiese articulado a través de una prestación social correspondiente, por ejemplo, tal como se ha diseñado la legislación de la Seguridad Social ${ }^{6}$, para el caso de menores afectados por cáncer u otras enfermedades graves, en los que se prevé un subsidio abonado en proporción a la reducción que experimente la jornada de trabajo $^{7}$, de tal forma que -en gran medida- la reducción operada por el cuidado directo y continuo del menor no afecta económicamente al progenitor que haya ejercitado su derecho.

\footnotetext{
${ }^{3}$ Véase AGUILERA IZQUIERDO, R., «Los derechos de conciliación de la vida personal, familiar y laboral en la Ley Orgánica para la igualdad efectiva de mujeres y hombres», Revista del Ministerio de Trabajo y Asuntos Sociales, núm. 2, 2007, pág. 69.

${ }^{4}$ Basta leer la campaña «Te corresponde. Nos corresponde», por ejemplo. Es una campaña de concienciación organizada por el Ministerio de Sanidad, Servicios Sociales e Igualdad, que tiene como objeto fomentar la igualdad entre hombres y mujeres, la corresponsabilidad y la conciliación de la vida personal, familiar y laboral. Se puede acceder a ella en el link: http://tecorrespondenoscorresponde.org/.

${ }^{5}$ Las medidas de conciliación se han dirigido fundamentalmente a las mujeres, contribuyendo a que la conciliación se considere como un "problema exclusivo de las mujeres», lo que es -0 , en mi opinión, debería ser- una falacia. Son datos del Ministerio de Sanidad, Servicios Sociales e Igualdad [http://www.msssi.gob.es/ssi/igualdadOportunidades/iEmpleo/corresponsabilidad.htm]

${ }^{6}$ Real Decreto Legislativo 8/2015, de 30 de octubre, por el que se aprueba el texto refundido de la Ley General de la Seguridad Social.

${ }^{7}$ Cfr. artículo 190.1 de la Ley General de la Seguridad Social: «A efectos de la prestación económica por cuidado de menores afectados por cáncer u otra enfermedad grave, se considera situación protegida la reducción de la jornada de trabajo de al menos un 50 por ciento que, de acuerdo con lo previsto en el párrafo tercero del artículo 37.6 del texto refundido de la Ley del Estatuto de los Trabajadores, lleven a cabo los progenitores, adoptantes, guardadores con fines de adopción o acogedores de carácter permanente, cuando ambos trabajen, para el cuidado directo, continuo y permanente del menor a su cargo afectado por cáncer (tumores malignos, melanomas y carcinomas) o por cualquier otra enfermedad grave que requiera ingreso hospitalario de larga duración, durante el tiempo de hospitalización y tratamiento continuado de la enfermedad».
} 
2. En todo caso, la cuestión que se quiere exponer de manera sucinta es cómo se resuelven los problemas que puedan surgir con el empleador para el caso de querer reducir la jornada a los fines de conciliar su vida personal o familiar y, sobre todo, en qué medida se diferencia jornada y turno, para el caso de que el sistema de trabajo implementado en la empleadora sea de esa naturaleza; todo ello bajo la perspectiva de la igualdad y la interdicción de la discriminación ${ }^{8}$. Siendo necesario recordar que «la interdicción de la discriminación por razón de sexo implica no sólo la proscripción de aquellos tratamientos peyorativos que se fundan ya en la pura y simple constatación del sexo de la persona, ya en la concurrencia de razones o circunstancias que tengan con el sexo una conexión directa e inequívoca, como sucede con el embarazo, elemento o factor diferencial que, por razones obvias, incide de forma exclusiva sobre las mujeres (SSTC 173/1994, de 7 de junio, F. 2; 136/1996, de 23 de julio, F. 5; 20/2001, de 29 de enero, F. 4; y 41/2002, de 25 de febrero, F. 3, entre otras muchas), sino también la adopción de medidas que tratan de asegurar la igualdad efectiva de trato $\mathrm{y}$ oportunidades de la mujer y del hombre, por lo que las medidas legales que tratan de compensar las desventajas reales que para el acceso al trabajo o la conservación de su empleo soporta la mujer a diferencia del hombre no podrían considerarse opuestas al principio de igualdad, sino, al contrario, dirigidas a eliminar situaciones de discriminación existentes, para hacer realidad la efectividad en el disfrute de los derechos exigida por el art. 9.2 CE (SSTC 128/1987, FF. 7 y ss.; 19/1989, F. 4; 28/1992, de 9 de marzo, F. 3; 229/1992, de 14 de diciembre, F. 2; 3/1993, de 14 de enero, F. 3; y 109/1993, de 25 de marzo, F. 5, por todas)» ${ }^{9}$.

\section{EL TIEMPO DE TRABAJO: LA JORNADA}

3. Es evidente que la relación laboral es de duración continua, es decir, nace para durar en el tiempo, sea determinado o indefinido, sin embargo, esto no quiere decir que la prestación laboral que implica se desarrolle ininterrumpidamente durante todo ese periodo, sino que será preciso establecer límites; límites que son precisamente los que fija la jornada de trabajo. Esta expresión refleja ya su contenido: «duración de la prestación diaria del trabajador, aunque pueda computarse tanto por días como por meses o años» ${ }^{10}$, y es lo que se deduce del artículo 34 del Estatuto de los Trabajadores $^{11}$, que se dedica a la exposición de la jornada desde un punto de vista legal y a incluir ya la mención a la conciliación ${ }^{12}$, a la que luego se dedicará el artículo 37.6,

\footnotetext{
${ }^{8}$ Sobre este tema, puede consultarse MUNÍN SÁNCHEZ, L. M., «La discriminación en la conciliación de la vida familiar y profesional. A propósito de una Sentencia del Tribunal Europeo de Derechos Humanos de 19 de febrero de 2013 [asunto García Mateos contra España]», Anuario de la Facultad de Ciencias del Trabajo de la Universidad de A Coruña, vol. 5, 2014.

${ }^{9}$ Son palabras de la Sentencia del Tribunal Constitucional núm. 26/2011, de 14 de marzo, Fundamento Jurídico núm. 3.

${ }^{10}$ Véase MARTÍN VALVERDE, A., RODRÍGUEZ-SAÑUDO, GUTIÉRREZ, F. y GARCÍA MURCIA, J., Derecho del Trabajo, Tecnos, 23ª edición, Madrid, 2014, p. 552.

${ }^{11}$ Decreto Legislativo $2 / 2015$, de 23 de octubre, por el que se aprueba el texto refundido de la Ley del Estatuto de los Trabajadores.

${ }^{12}$ Puntos sustanciales de esta regulación serán: «1. La duración de la jornada de trabajo será la pactada en los convenios colectivos o contratos de trabajo. La duración máxima de la jornada ordinaria de trabajo será de cuarenta horas semanales de trabajo efectivo de promedio en cómputo anual.

2. Mediante convenio colectivo o, en su defecto, por acuerdo entre la empresa y los representantes de los trabajadores, se podrá establecer la distribución irregular de la jornada a lo largo del año [...]
} 
siquiera se siga hablando de la productividad de la empresa como uno de los elementos para articular ese derecho, lo que supone confrontar intereses, que -en mi opinióndeberían situarse en planos distintos -y en un superior el derecho a la conciliación-, tal y como, por otra parte, se deduce de la jurisprudencia constitucional ${ }^{13}$.

Podríamos concluir que jornada de trabajo es el tiempo que el trabajador dedica a cumplir su contrato de trabajo ${ }^{14}$; en sentido estricto, la jornada es el único periodo de tiempo que merece el calificativo de verdadero tiempo de trabajo ${ }^{15}$. Sin embargo, ese tiempo de trabajo está limitado por el derecho a descansar -lo que supone un tiempo de descanso obligatorio-; y, además, porque existen determinados tiempos de descanso asimilados (por ejemplo, las vacaciones) al tiempo de trabajo, dado que se retribuyen ${ }^{16}$.

Y, conforme al artículo 2.1 de la Directiva 2003/88/CE del Parlamento Europeo y del Consejo, de 4 de noviembre de 2003, relativa a determinados aspectos de la ordenación del tiempo de trabajo ${ }^{17}$, es tiempo de trabajo «todo periodo durante el cual el trabajador permanezca en el trabajo, a disposición del empresario y en ejercicio de su actividad o de sus funciones, de conformidad con las legislaciones y/o prácticas nacionales», que es concepto acogido por la jurisprudencia nacional ${ }^{18}$; precisándose por la comunitaria ${ }^{19}$ que el concepto «tiempo de trabajo» ha de ser entendido como todo período durante el cual el trabajador permanece en el trabajo, a disposición del empresario y en ejercicio de su actividad o de sus funciones, de conformidad con las legislaciones y/o prácticas nacionales, y que este concepto se concibe en contraposición

3. Entre el final de una jornada y el comienzo de la siguiente mediarán, como mínimo, doce horas. El número de horas ordinarias de trabajo efectivo no podrá ser superior a nueve diarias, salvo que por convenio colectivo o, en su defecto, acuerdo entre la empresa y los representantes de los trabajadores, se establezca otra distribución del tiempo de trabajo diario, respetando en todo caso el descanso entre jornadas $[\ldots]$

5. El tiempo de trabajo se computará de modo que tanto al comienzo como al final de la jornada diaria el trabajador se encuentre en su puesto de trabajo [...]

8. El trabajador tendrá derecho a adaptar la duración y distribución de la jornada de trabajo para hacer efectivo su derecho a la conciliación de la vida personal, familiar y laboral en los términos que se establezcan en la negociación colectiva o en el acuerdo a que llegue con el empresario respetando, en su caso, lo previsto en aquella.

A tal fin, se promoverá la utilización de la jornada continuada, el horario flexible u otros modos de organización del tiempo de trabajo y de los descansos que permitan la mayor compatibilidad entre el derecho a la conciliación de la vida personal, familiar y laboral de los trabajadores y la mejora de la productividad en las empresas»).

${ }^{13}$ Véanse las Sentencias del Tribunal Constitucional núm. 3/2007, de 15 de enero; núm. 24/2011, de 14 de marzo; y núm. 26/2011, de 14 de marzo.

${ }^{14}$ Véase GARCÍA NINET, J. I., Jornada de trabajo. Horario y horas extraordinarias, Edersa, Madrid, 1977 , pp. 121 y ss.

${ }^{15}$ Véase MARTÍNEZ GIRÓN, J., ARUfE VARELA, A. y CARRIL VÁZQUEZ, X. M., Derecho del Trabajo, Netbiblo, $2^{\mathrm{a}}$ edición, A Coruña, p. 197.

${ }^{16}$ Cfr. ALARCÓN CARACUEL, M. R., La ordenación del tiempo de trabajo, Tecnos, Madrid, 1988, pp. 28 y ss.

${ }^{17}$ Véase ALFONSO MELLADO, C. L. y GARCÍA ORTEGA, J., Jornada y ordenación del tiempo de trabajo, Tirant lo Blanch, Valencia, 1996, pp. 19 y ss.

${ }^{18}$ Véanse las Sentencias del Tribunal Supremo de 9 de diciembre de 2003 -Recurso de casación para unificación de doctrina núm. 2358/2002-; y de 6 de octubre de 2008 -Recurso de casación ordinaria núm. 177/2 007-.

${ }^{19}$ A la que se refiere las Sentencias del Tribunal Supremo de 8 de junio de 2006 -Recurso de casación para unificación de doctrina núm. 1693/2005-; y de 4 de julio de 2006-Recurso de casación para unificación de doctrina núm. 858/2005-. 
al de período de descanso, al excluirse mutuamente ambos conceptos ${ }^{20}$; esto supone que la referida Directiva 93/104 no contempla una categoría intermedia entre los períodos de trabajo y los de descanso, y entre los elementos peculiares del concepto de «tiempo de trabajo» no figura la intensidad del trabajo desempeñado por el trabajador por cuenta ajena ni el rendimiento de éste, por lo que el hecho de que, por ejemplo, los servicios de guardia comporten ciertos períodos de inactividad carece de relevancia ${ }^{21}$; razón por la cual estos servicios en régimen de presencia física en el centro laboral deben considerarse tiempo de trabajo en su totalidad, independientemente de las prestaciones laborales realmente efectuadas por el interesado ${ }^{22}$; y, también, que a pesar de que los períodos de inactividad profesional son inherentes al servicio de guardia que el trabajador efectúa en régimen de presencia física en el centro laboral, el factor determinante es el hecho de que dicho trabajador está obligado a estar físicamente en el lugar determinado por el empresario y a permanecer a disposición de éste para poder realizar de manera inmediata las prestaciones adecuadas en caso de necesidad ${ }^{23}$. Aparte de que en este tiempo de trabajo (jornada) también se incluiría el de desplazamiento que los trabajadores, que carecen de centro de trabajo fijo o habitual, dedican a moverse diariamente entre su domicilio y los centros del primer y del último cliente que les asigna su empresario ${ }^{24}$; y, también, «que la posibilidad de que los trabajadores gestionen su tiempo con menos limitaciones y se dediquen a sus asuntos personales es un elemento que permite afirmar que el período de tiempo examinado no constituye tiempo de trabajo en el sentido de la Directiva 2003/88 (véase, en este sentido, la sentencia Simap, C-303/98, EU:C:2000:528, apartado 50)» ${ }^{25}$; en caso contrario, «tendría como efecto la desnaturalización de este concepto y el menoscabo del objetivo de protección de la seguridad y de la salud de estos trabajadores»» ${ }^{26}$.

En atención a lo expuesto $-\mathrm{y}$ a los diversos planteamientos científicos-, podría concluirse que la jornada es un concepto más amplio que el de la jornada de trabajo, pues ésta -conforme al artículo 34.1 del Estatuto de los Trabajadores- se refiere al tiempo de servicios efectivamente prestados por el trabajador como pago de su deuda de actividad: el tiempo que «en cómputo diario, semanal o anual, dedica el trabajador a su cometido laboral propio» -entendido en los términos expresados por la jurisprudencia comunitaria-; mientras que el concepto sociológico de jornada alude a todo el tiempo de presencia física del trabajador en la empresa o centro de trabajo, por lo que la jornada

\footnotetext{
${ }^{20}$ Véanse las Sentencias del Tribunal de Justicia de las Comunidades Europeas de 3 de octubre de 2000, asunto C-303/98, conocido como Asunto SIMAP, apartado 47; de 9 de septiembre de 2004, Asunto C151/2002, conocido como Asunto Jaeger, apartado 48, y de 1 de diciembre de 2005, Asunto C-14/04, conocido como Asunto Dellas, apartado 42.

${ }^{21}$ Véase la Sentencia del Tribunal de Justicia de las Comunidades Europeas de 1 de diciembre de 2005, Asunto C-14/04, conocido como Asunto Dellas, apartados 42 y 47.

${ }^{22}$ Véanse las Sentencias del Tribunal de Justicia de las Comunidades Europeas de 3 de octubre de 2000, asunto C-303/98, conocido como Asunto SIMAP, apartado 52; de 9 de septiembre de 2004, Asunto C151/2002, conocido como Asunto Jaeger, apartados 71, 75 y 103; y de 1 de diciembre de 2005, Asunto C14/04, conocido como Asunto Dellas, apartado 46.

${ }^{23}$ Véanse las Sentencias del Tribunal de Justicia de las Comunidades Europeas de 3 de octubre de 2000, asunto C-303/98, conocido como Asunto SIMAP, apartado 48; de 9 de septiembre de 2004, Asunto C151/2002, conocido como Asunto Jaeger, apartados 49 y 63; y de 1 de diciembre de 2005, Asunto C14/04, conocido como Asunto Dellas, apartado 48.

${ }^{24}$ Véanse las Sentencias del Tribunal de Tribunal de Justicia de la Unión Europea (Sala Tercera) de 10 de septiembre de 2015, asunto C-266/14, conocido como Asunto Tyco, apartados 25 y ss.

25 Ídem, apartado 35.

26 Ídem, apartado 32.
} 
diaria, que no la «jornada de trabajo», viene a ser entonces la suma del tiempo de trabajo efectivo, más el tiempo de descanso ${ }^{27}$.

4. El otro punto importante en el tema es la distribución del tiempo de trabajo, que, entre otras y para lo que afecta a la cuestión a la que se intenta dar respuesta (la concreción horaria en supuesto de trabajadores a turnos), hace que se puedan establecer turnos de trabajo, que el artículo 36.3 del Estatuto de los Trabajadores define como «toda forma de organización del trabajo en equipo según la cual los trabajadores ocupan sucesivamente los mismos puestos de trabajo, según un cierto ritmo, continuo o discontinuo, implicando para el trabajador la necesidad de prestar sus servicios en horas diferentes en un periodo determinado de días o de semanas»; que -además- implica, para las empresas cuya actividad se desarrolla a lo largo de todos los días de la semana «incluidos los domingos y días festivos», dice el precepto estatutario-, la posibilidad de optar por dos sistemas de organizar y cubrir esos turnos permanentes: uno, «equipos de trabajadores que desarrollen su actividad por semanas completas», de tal forma que después disfruten su descanso; o dos, «personal para completar los equipos necesarios durante uno o más días a la semana», es decir, se trataría de trabajadores a tiempo parcial, conforme a la modalidad prevista en el artículo 12 del Estatuto de los Trabajadores.

5. Y será precisamente en estos supuestos de jornada organizada a través de turnos en los que surja el problema de la aplicación del artículo 37.6 del Estatuto de los Trabajadores, porque, y esto debe quedar claro, primero es necesario proceder a una reducción de jornada, para luego solicitar y concretar dicha reducción, surgiendo los previos problemas relativos a la reducción. Esta afirmación es lógica y, además, se deduce del artículo 37.7 del Estatuto de los Trabajadores, al decir: «los convenios colectivos podrán establecer criterios para la concreción horaria de la reducción de jornada a que se refiere el apartado 6». En otras palabras, que la reducción de jornada disminuir el tiempo de trabajo- será un paso previo a la concreción que se va a producir con esa reducción. De tal forma que el trabajador que no haga uso de la reducción verá imposibilitada la concreción, por ejemplo, para no trabajar los fines de semana o elegir un turno determinado, lo que tendrá su propia vía de ejercicio, a tenor de lo dispuesto en el artículo 34.8 del Estatuto de los Trabajadores que exigirá su desarrollo convencional o arriesgarse a convertirse en una mera proclamación programática.

El primer punto relevante en este ámbito será saber qué tipo de jornada se puede reducir, porque podría ocurrir que dicha reducción se produjese sobre la diaria, la semanal, la mensual o la anual. El primitivo régimen del derecho de reducción de jornada introducía la duda de qué tipo de jornada se podía emplear; de forma tal que no se determinaba si podría actuar sobre módulos temporales superiores al diario, al hablar tan solo de «jornada ordinaria»; y ello, beneficiaba al trabajador que quisiese reducir la jornada, porque podría hacerlo sobre un cómputo semanal y excluir determinados días los fines de semana, por ejemplo-; o, también, en cómputo anual y librar, por ejemplo, el periodo estival, habida cuenta de las largas vacaciones escolares y la falta de coordinación con las laborales. Es más, hubo algún pronunciamiento judicial en este

\footnotetext{
${ }^{27}$ Véanse las Sentencias del Tribunal Supremo de 6 de marzo de 2000 -Recurso de casación ordinaria núm. 1217/199; y de 21 de octubre de 1994 -Recurso de casación ordinaria núm. 600/1994.
} 
sentido $^{28}$, siquiera de una manera muy desleída, sin que se mostrase un criterio asentado en dicha línea, sino todo lo contrario, porque la mayoría de las resoluciones judiciales lo interpretaron como jornada diaria, que - precisamente- ha sido como se configuró, al hablarse ahora -al mencionar la concreción- en la «jornada diaria», con lo que las posibilidades se contraen bastante para las personas trabajadoras.

Y el segundo, que tiene mayor trascendencia práctica, es si esa regla que impone el artículo citado es de ius cogens o de derecho dispositivo, de tal forma que pudiese ser modificada por convenio colectivo o, también, por un acuerdo individual ${ }^{29}$. De entrada, hubiese sido mucho mejor que el Legislador hubiese atribuido uno u otro carácter de manera expresa y, mucho mejor, directamente -como ha hecho en otras materias mucho menores- una naturaleza dispositiva, que autorizase la posibilidad de que la autonomía de la voluntad pudiese alterar dicha regla estatutaria, flexibilizando lo que se presenta qué duda cabe- como un régimen excesivamente rígido $-\mathrm{y}$, en mi opinión- contrario a los fines que han de inspirar la conciliación familiar y personal y a los que se han hecho referencia al comienzo de este escrito, porque no parece, sobre su dicción literal, que esa haya sido la intención del Legislador. Ello es doblemente desconcertante desde el punto y hora en que el apartado siguiente -el artículo 37.7 del Estatuto de los Trabajadores- habla de jornada ordinaria y da flexibilidad al sistema implantado.

\section{LA CONCILIACIÓN DE LA VIDA PERSONAL, FAMILIAR Y PROFESIONAL}

\section{Formas de hacerlo efectivo}

6. Se ha puesto fin al debate interpretativo sobre la «jornada ordinaria», que debe entenderse ya -a los efectos del artículo 37.6 del Estatuto de los Trabajadores- como «jornada diaria», que será sobre la que la persona trabajadora deberá solicitar su reducción. Una vez realizada ésta, el siguiente paso natural es el de concretar esa jornada reducida y lo más importante es si el trabajador (o, habitualmente, trabajadora) puede hacerlo sólo por la mañana, por ejemplo, eligiendo un turno de mañana o/y sólo de lunes a viernes, excluyendo el sábado, cuando el sistema elegido por la empresa y su horario incluye también la prestación de servicios los sábados e, incluso, determinados domingos y festivos. El artículo 37.6 del Estatuto de los Trabajadores establece en su párrafo primero que «[q]uien por razones de guarda legal tenga a su cuidado directo algún menor de doce años o una persona con discapacidad que no desempeñe una actividad retribuida tendrá derecho a una reducción de la jornada de trabajo diaria, con la disminución proporcional del salario entre, al menos, un octavo y un máximo de la mitad de la duración de aquella», añadiendo en su último párrafo que «[1]as reducciones de jornada contempladas en este apartado constituyen un derecho individual de los trabajadores, hombres o mujeres. No obstante, si dos o más trabajadores de la misma empresa generasen este derecho por el mismo sujeto causante, el empresario podrá limitar su ejercicio simultáneo por razones justificadas de funcionamiento de la

\footnotetext{
${ }^{28}$ Cfr. Sentencia de la Audiencia Nacional de 8 de febrero de 2007 -Procedimiento núm. 189/2006-.

${ }^{29}$ Sobre el particular, puede verse MONTOYA MEDINA, « La conciliación de la vida laboral y familiar en la reforma laboral de 2012», Elderecho.com, consultado online.
} 
empresa». A continuación el apartado 7 del artículo 37 del Estatuto de los Trabajadores, introducido por el número 3 del artículo 2 de la Ley 39/1999, 5 noviembre, para promover la conciliación de la vida familiar y laboral de las personas trabajadoras, establece también que: «La concreción horaria y la determinación del periodo de disfrute del permiso de lactancia y de la reducción de jornada, previstos en los apartados 4 y 6 , corresponderán al trabajador, dentro de su jornada ordinaria. No obstante, los convenios colectivos podrán establecer criterios para la concreción horaria de la reducción de jornada a que se refiere el apartado 6, en atención a los derechos de conciliación de la vida personal, familiar y laboral del trabajador y las necesidades productivas y organizativas de las empresas. El trabajador, salvo fuerza mayor, deberá preavisar al empresario con una antelación de quince días o la que se determine en el convenio colectivo aplicable, precisando la fecha en que iniciará y finalizará el permiso de lactancia o la reducción de jornada.

Las discrepancias surgidas entre empresario y trabajador sobre la concreción horaria y la determinación de los periodos de disfrute previstos en los apartados 4, 5 y 6 serán resueltas por la jurisdicción social a través del procedimiento establecido en el artículo 139 de la Ley 36/2011, de 10 de octubre, Reguladora de la Jurisdicción Social».

Dicho precepto, redactado en su origen por la Ley 39/1999, de 5 de noviembre, para promover la conciliación de la vida familiar y laboral de las personas trabajadoras, se incluye como cumplimiento del deber de los poderes públicos de asegurar la protección social y económica y jurídica de la familiar prevista en el artículo 39.1 de la Constitución Española ${ }^{30}$, efectuando en la referida Ley, la transposición a la legislación española de la normativa internacional y comunitaria, concretamente las Directivas del Consejo 92/85, 19 de octubre y 96/34, 3 de junio.

7. El derecho de los trabajadores para elegir el horario más acorde con el cumplimiento de sus obligaciones en caso de guarda legal ya aparecía recogido antes de la reforma legislativa por reiteradas sentencias de nuestros Tribunales Superiores de Justicia y, definitivamente, por el Tribunal Supremo en Sentencia de fecha de 20 de julio de 2000 -Recurso de casación para la unificación de doctrina núm. 3799/1999-, que señalaba que «la aplicación de las reducciones de jornada que establece el artículo 37.5 [actual 37.6] Estatuto de los Trabajadores, ha de partirse de la base de que tal precepto forma parte del desarrollo del mandato constitucional (artículo 39 de la Constitución) que establece la protección a la familia y a la infancia. Finalidad que ha de prevalecer y servir de orientación para la solución de cualquier duda interpretativa; y en la posterior sentencia de 11 de diciembre de 2001 (rec. 1817/2001), con cita de la anterior, decíamos, que los supuestos de jornada reducida por guarda legal, "tienden a proteger no solo el derecho de los trabajadores a conciliar su vida laboral y familiar para mejor cumplir con los deberes inherentes a la patria potestad que enumera el art. 154.1 del Código Civil, sino también el propio interés del menor a recibir la mejor atención posible" $\gg{ }^{31}$. Es cierto que la propia norma admite la posibilidad de existencia de discrepancias surgidas en la concreción horaria $y$ que, según reiterados pronunciamientos judiciales, esta concreción debe de estar presidida por los principios

\footnotetext{
${ }^{30}$ «Los poderes públicos aseguran la protección social, económica y jurídica de la familia»-artículo 39.1 de la Constitución Española-.

${ }^{31}$ Son palabras de la Sentencia del Tribunal Supremo de 13 de junio de 2008 -Recurso de casación para la unificación de doctrina núm. 897/2007-.
} 
de la buena fe sin causar arbitraria y caprichosamente alteraciones o perjuicios innecesarios en la organización y distribución del trabajo que afecten al empresario y compañeros.

Pese a ello, el Tribunal Supremo ${ }^{32}$ fundamenta su decisión de limitar el ejercicio del derecho a la concreción horaria, dentro de la jornada laboral, en base al principio de legalidad $^{33}$; esto implica que la jurisprudencia ordinaria descarta la posibilidad de una hermenéutica expansiva de los párrafos sexto y séptimo del citado artículo 37 del Estatuto de los Trabajadores para incluir el cambio de turno como derecho de conciliación de la vida personal, familiar y laboral; salvo -ya se apuntaba antes- lo previsto en el artículo 34, pero en las especiales condiciones prevista en él, habida cuenta que el reconocimiento se mediatiza al previo acuerdo entre el empleado y su empleador o, en su caso, cuando el convenio colectivo lo pueda prever ${ }^{34}$.

Sin embargo, el Tribunal Constitucional sí ha tenido oportunidad de pronunciarse en torno al cambio de turno de un trabajador y relacionarlo -como no podía ser menos- con el derecho a la no discriminación-del artículo 14 de la Constitución Española ${ }^{35}$ - y la tutela jurisdiccional efectiva -del artículo 24.1 del mismo texto $^{36}$ - en las Sentencias del Tribunal Constitucional núm. 3/2007, de 15 de enero; núm. 24/2011, de 14 de marzo; y núm. 26/2011, de 14 de marzo ${ }^{37}$. En todas estas sentencias el Alto Tribunal denuncia que en las resoluciones de jurisdicción ordinaria falta una argumentación jurídica sólida -e, incluso, motivación-, desde el punto de vista de la protección constitucional de los derechos de conciliación de la vida personal, familiar y laboral ${ }^{38}$. Esto conduce a que exija que en las sentencias que resuelven sobre el ejercicio de dichos derechos de conciliación -y la concreción lo es- se analicen los motivos, circunstancias particulares, tanto de la empresa como del trabajador para conceder o denegar el cambio de turno; y, por ello mismo, se recomienda que las trabajadoras $-\mathrm{o}$ trabajadores- cuando solicitan el cambio de turno debe fundamentar su

\footnotetext{
${ }^{32}$ Véase la Sentencia del Tribunal Supremo de 21 de marzo de 2011 -Recurso de casación ordinaria núm. 54/2010-.

${ }^{33}$ Cfr. UBILLÚS BRACAMONTE, R. E., «La concreción horaria y la reducción de la jornada por cuidado de hijo menor», Aranzadi Social, núm. 21, 2013, consultado a través de la base de datos Westlaw (BIB 2013/1184).

${ }^{34}$ Véase SEMPERE NAVARRO, A. V. y CHARRO BAENA, P., «Adaptación del horario de trabajo por cuidado de un hijo discapacitado», Aranzadi Social, núm. 22, 2008, consultado a través de la base de datos Westlaw (BIB 2008/2713).

35 «Los españoles son iguales ante la ley, sin que pueda prevalecer discriminación alguna por razón de nacimiento, raza, sexo, religión, opinión o cualquier otra condición o circunstancia personal o social» artículo 14-.

${ }^{36}$ «Todas las personas tienen derecho a obtener la tutela efectiva de los jueces y tribunales en el ejercicio de sus derechos e intereses legítimos, sin que, en ningún caso, pueda producirse indefensión» -artículo 24.1-.

37 Para un análisis más profundo sobre ellas, se puede leer MONTOYA MEDINA, D., «Dimensión constitucional de los derechos de conciliación de la vida laboral, personal y familiar (comentario a las SSTCO 24/2011 y 26/2011, de 14 de marzo)», Aranzadi Social, núm. 4, 2011, consultado a través de la base de datos Westlaw (BIB 2011/1031); y, también, SÁNCHEZ-URÁN AZAÑA, Y., «Adaptación de la jornada laboral por circunstancias familiares: la familia como bien jurídico protegido (Reflexiones en torno a la STC 24/2011)», Nueva Revista Española de Derecho del Trabajo, núm. 155, 2012.

38 «el reproche [...] "no es tanto ni sólo que haya renunciado a interpretar la normativa aplicable de la manera más favorable a la efectividad del derecho fundamental, sino que ni siquiera haya tenido en cuenta que este derecho estaba en juego y podía quedar afectado" (SSTC 191/1998, de 29 de septiembre, F. 5; 92/2005, de 18 de abril, F. 5; y 3/2007, de 15 de enero, F. 6)»-son palabras de la Sentencia del Tribunal Constitucional núm. 26/2011, de 14 de marzo, Fundamento Jurídico núm. 6.
} 
solicitud en sus especiales circunstancias concurrente (a saber, número de hijos, edades, cuál es la jornada de su cónyuge); pero -a la vez- el empleador debe tratar de agotar todas las posibilidades para ajustarse a la solicitud del empleado y, en caso contrario, deberá justificar debidamente cuáles son esas dificultades. En definitiva, «la dimensión constitucional de las medidas normativas tendentes a facilitar la conciliación de la vida familiar y laboral de las personas trabajadoras, tanto desde la perspectiva del derecho a la no discriminación por razón de las circunstancias personales (art. $14 \mathrm{CE}$ ), como desde la perspectiva del mandato de protección a la familia y a la infancia (art. $39 \mathrm{CE}$ ), debe prevalecer y servir de orientación para la solución de cualquier duda interpretativa que pueda suscitarse ante la aplicación a un supuesto concreto de una disposición que afecte a la conciliación profesional y familiar. Ello obligaba en el presente caso a valorar las concretas circunstancias personales y familiares que concurrían en el trabajador demandante, así como la organización del régimen de trabajo de la residencia de educación especial en la que prestaba servicios, para ponderar si la negativa empresarial a su pretensión de trabajar en horario nocturno constituía o no un obstáculo injustificado para la compatibilidad de su vida familiar y profesional» ${ }^{39}$.

8. Como corolario y opinión personal, la concreción horaria de la reducción de jornada es un derecho del trabajador que la solicita, que sólo en supuestos muy excepcionales ha de decaer, como en caso de abuso de derecho, inexistencia de buena fe o manifiesto quebranto para la empresa; lo que ocurre es que la interpretación de estas circunstancias debe hacerse de manera restrictiva, porque no es concebible que la organización empresarial -o las molestias que se le puedan ocasionar-, sobre todo en el caso de empresas con muchos empleados puede emplearse como excusa para restringir un derecho básico. Fuera de ello, la primacía ha de otorgarse -ese es el sentido que ofrece la jurisprudencia constitucional- a la efectividad del derecho, pese a la dicción literal; y, además, es el criterio que se está imponiendo en los órganos de Instancia.

\section{Procedimiento para dirimir las discrepancias}

9. El artículo 37.7 del Estatuto de los Trabajadores -ya citado- remite a la regulación del artículo 139 de la Ley Reguladora de la Jurisdicción Social, que regula la modalidad procesal de derechos de conciliación. Sobre este procedimiento ${ }^{40}$, se podrían aclarar los siguientes puntos conflictivos: (a) su objeto consiste en las discrepancias o negativa empresarial en torno al ejercicio de los derechos de conciliación y, entre ellos, el de la concreción horaria en la jornada; (b) las actuaciones preprocesales consistirán, necesariamente, en la solicitud del disfrute o de la concreción horaria por parte del trabajador y en una respuesta por parte del empresario, que, de no hacerlo, habría que considerar -en atención a los intereses confluyentes y a la perentoriedad de su ejercicioque es una aceptación tácita a la petición del empleado; (c) no existe más partes -a diferencia del proceso por vacaciones, por ejemplo- que el empresario y el trabajador solicitante, siquiera podría ser interesante que otros trabajadores que estuviesen disfrutando de similar derecho o interesados puedan participar como coadyuvantes; (d)

\footnotetext{
${ }^{39}$ Son palabras de la Sentencia del Tribunal Constitucional núm. 26/2011, de 14 de marzo, Fundamento Jurídico núm. 6.

${ }^{40}$ Sobre el tema, puede consultarse LOUSADA AROCHENA, F. y RON LATAS, R. P. [Coord.], Sistema de derecho procesal laboral, Laborum, Madrid, 2015, pp. 288 a 293.
} 
el plazo para acudir al proceso es -así lo expresa el propio precepto procesal- de caducidad, idéntico al fijado para el despido: 20 días; (e) el procedimiento es urgente y de tramitación preferente; y (f) la decisión es irrecurrible, salvo que el trabajador hubiese acumulado una acción de daños (para resarcirse de los causados ante la negativa del empresario, lo que exigirá probar las bases necesarias para fijar dicha indemnización).

\section{CONCLUSIONES}

10. La conciliación de la vida personal, familiar y profesional es una de las manifestaciones más importantes para lograr, entre otros objetivos, la igualdad efectiva de hombres y mujeres, esto es, la participación equilibrada entre mujeres y hombres en la vida familiar $y$ en el mercado de trabajo, mediante la reestructuración y reorganización de los sistemas, laboral, educativo y de recursos sociales, con el fin de introducir la igualdad de oportunidades en el empleo, variar los roles y estereotipos tradicionales, y cubrir las necesidades de atención y cuidado a personas dependientes. Y, precisamente, uno de los medios más eficaces para conseguirlo -aparte de otros muchos- será la reducción de la jornada de trabajo, de tal forma que se pueda acortar el tiempo dedicado a la prestación de servicios, aunque suponga una reducción correlativa del salario; consecuencia que debería - de lege ferenda-suplirse a través de un subsidio como el que existe en otras situaciones.

Esa reducción de jornada es un paso previo -así lo viene manteniendo la jurisprudencia- para conseguir concretar el horario de los trabajadores, pero el punto más importante de fricción lo constituye la manera en la que se concreta, puesto que el trabajador tendrá como objetivo excluir determinados turnos, no prestar servicios los fines de semana o, incluso, en determinadas temporadas; sin embargo, las resoluciones judiciales se han decantado por limitar esta posibilidad -ajustándose a una interpretación literal del artículo 37 del Estatuto de los Trabajadores- dentro de la jornada ordinaria. Ha tenido que ser el Tribunal Constitucional el que abriese la puerta a una flexibilización en este campo, censurando las decisiones de la jurisdicción ordinaria y marcando la primacía de los derechos de conciliación de vida personal, familiar y profesional. En todo caso, queda mucho camino por recorrer y será preciso la reforma de la legislación estatutaria a fin no sólo de conceder una mayor flexibilidad-como se hace en otros ámbitos-, sino de impulsar las medidas de conciliación.

\section{BIBLIOGRAFÍA}

AGUILERA IZQUIERDO, R., "Los derechos de conciliación de la vida personal, familiar y laboral en la Ley Orgánica para la igualdad efectiva de mujeres y hombres», Revista del Ministerio de Trabajo y Asuntos Sociales, núm. 2, 2007.

ALARCÓN CARACUEL, M. R., La ordenación del tiempo de trabajo, Tecnos, Madrid, 1988 
ALFONSO MELLADO, C. L. y GARCÍA ORTEGA, J., Jornada y ordenación del tiempo de trabajo, Tirant lo Blanch, Valencia, 1996

FUNDACIÓN MUJERES, Conciliación de la vida laboral, familiar y personal, Ministerio de Igualdad, Madrid, 2010

GARCÍA NINET, J. I., Jornada de trabajo. Horario y horas extraordinarias, Edersa, Madrid, 1977

LOUSADA AROCHENA, F. y RON LATAS, R. P. [Coord.], Sistema de derecho procesal laboral, Laborum, Madrid, 2015

MARTÍN VALVERDE, A., RODRÍGUEZ-SAÑUDO, GUTIÉRREZ, F. y GARCÍA MURCIA, J., Derecho del Trabajo, Tecnos, 23ª edición, Madrid, 2014

MARTÍNEZ GIRÓN, J., ARUFE VARELA, A. y CARRIL VÁZQUEZ, X. M., Derecho del Trabajo, Netbiblo, $2^{\mathrm{a}}$ edición, A Coruña

MONTOYA MEDINA, «La conciliación de la vida laboral y familiar en la reforma laboral de 2012», Elderecho.com, consultado online

MONTOYA MEDINA, D., «Dimensión constitucional de los derechos de conciliación de la vida laboral, personal y familiar (comentario a las SSTCO 24/2011 y 26/2011, de 14 de marzo)», Aranzadi Social, núm. 4, 2011, consultado a través de la base de datos Westlaw (BIB 2011/1031).

MUNÍN SÁNCHEZ, L. M., «La discriminación en la conciliación de la vida familiar y profesional. A propósito de una Sentencia del Tribunal Europeo de Derechos Humanos de 19 de febrero de 2013 [asunto García Mateos contra España]», Anuario de la Facultad de Ciencias del Trabajo de la Universidad de A Coruña, vol. 5, 2014

SÁNCHEZ-URÁN AZAÑA, Y., «Adaptación de la jornada laboral por circunstancias familiares: la familia como bien jurídico protegido (Reflexiones en torno a la STC 24/2011)», Nueva Revista Española de Derecho del Trabajo, núm. 155, 2012.

SEMPERE NAVARRO, A. V. y CHARRO BAENA, P., «Adaptación del horario de trabajo por cuidado de un hijo discapacitado», Aranzadi Social, núm. 22, 2008

UBILLÚS BRACAMONTE, R. E., «La concreción horaria y la reducción de la jornada por cuidado de hijo menor», Aranzadi Social, núm. 21, 2013, consultado a través de la base de datos Westlaw (BIB 2013/1184) 